\title{
NEW DIRECTION TO KNOWLEDGE AND TECHNOLOGY DRIVEN DEVELOPMENT ACCORDING FOR SOME EUROPEAN REGIONS
}

\author{
Henrietta Nagy, ${ }^{1}$ Balázs Illés, ${ }^{2}$ József Káposzta, ${ }^{3}$ \\ 1,2,3 Institute of Regional Development and Rural Economics \\ Faculty of Economics and Social Sciences \\ Szent Istvan University, Gödöllő H-2100, Hungary \\ Nagy.Henrietta@gtk.szie.hu, illesbalazs@hotmail.com; kaposzta.jozsef@gtk.szie.hu
}

\begin{abstract}
The link between knowledge and wealth is considered as a proven fact in general and sometimes also on a regional level. Studies assume that services and products with higher added value have better profitability therefore they can create higher welfare for the producing company and finally to the region as well where it is located. We wanted to create a proper framework for clusters of knowledge intensive sectors and compare the specialization and concentration of the knowledge intenvise sectors in a European level to confirm, reject or modify these general assumptions. For that we used several approaches (purely regional, regional and sectoral, etc) and in this paper we would like to present our findings for the different sectors we investigated. Our reserach is based on Eurostat employment data, calculating regional location quotient from 1994 to 2008 and comparing these data with the GDP per capita values from the regions.
\end{abstract}

Keywords: Knowledge intensive sectors, Quality of life, Employment, Knowledge driven industry

\section{Introduction}

The literature specifies those branches and sectors (traded, basic, export branches) that can lead a region into economic development and success. Porter (2003) names all the 41 sectors that are able to cluster in the U.S. Ketels and Sölvell (2005) defined 38 traded clusters which used four-digit NACE rev 2. (Statistical classification of economic activities in the European Union) classification, where 302 subsectors have been considered from all
Professional Paper doi:10.5937/jouproman5-13667 the 615. Ketels and Protsiv (2014) provided there summary on cluster mapping methodology where 51 traded clusters have been declared, which overlaps $70 \%$ of the subsectors and $80 \%$ of the employees of these sectors within the previous studies. Beside these sectors Eurostat also separates different branches according to their knowledge intensity which will be introduced later. If we accept the theory of innovation driven development and the statements of Porter (2003) about traded cluster, then we should only focus on the impact of these branches on quality of life. Ketels and Sölvell (2005) have made already these kinds of studies about the regional economic performance and clusters. In a broader perspective it is conceivable that small local clusters with non-traded activities (such as craftsmanship or culinary products) can connect local suppliers and producers and these clusters can have impact on their surrounding region as it was observed by tourism by Szanyi et al (2009). In this thesis these kind of nontraded clusters are no investigated. When selecting and standardizing the data should be respected sectors that are able create trade clusters and through their concentration they can contribute to regional development. 


\section{Method and database}

Eurostat has a so called high-tech industry and knowledge intensive service database ${ }^{1}$ which was used and filtered to the employment data in order to calculate labor based LQ. The database lasts from 1994 to 2008 and shows the employment in the different knowledge intensive sectors on regional levels of NUTS0, NUTS1 and NUTS2 in 33 countries. The separation of the different sectors according to their knowledge level is based on a sectoral and a product based approach. Sectoral breakdown is based on the $\mathrm{R}+\mathrm{D}$ costs and the added value of the certain industry using NACE rev. 1.1. ${ }^{2}$ data and so called high-tech, medium high-tech, medium low-tech, and low-tech industries appear in manufacturing. Considering reliability and accessibility of the data NACE uses only divisional, and two-digit sectoral breakdown. By using this knowledge based approach we tried to avoid the failure that is mentioned by Szanyi et al (2009) that referred to intensity of work and the sectoral breakdown. About the failures of using simply a sectoral breakdown Monfardini et. al (2012) made a comprehensive summary. We were not focusing on designing a new and more appropriate identification of the different branches but to study their link with quality of life so we accepted the mentioned knowledge based breakdown of NACE. For services knowledge intensive and less knowledge intensive sectors are identified and the basis of this calculation is the share of

\footnotetext{
1

http://appsso.eurostat.ec.europa.eu/nui/show.do?dat aset=htec_emp_reg\&lang=en

${ }^{2}$ NACE Rev.1.1: Nomenclature Générale des Activités Economiques dans les Communautés Européennes,

(Statistical classification of economic activities in the European Community) - The Statistical classification of economic activities in the European Community between 2002 and 2008
}

employees with tertiary educationdegree. In the research period the classification changed twice ${ }^{3}$, so NACE Rev. 1.1 and NACE rev. 2. could give a different approach to knowledge intensity. Eurostat realized that and the database has been corrected so the categories are identical for the whole period of the study.

Besides sectoral approach product based approach is also considered in this database. Product based approach handles $\mathrm{R}+\mathrm{D}$ costs and revenue according to Standard International Trade Classification (SITC Rev.4.) ${ }^{4}$. Standard International Trade Classification also changed in that period so in 2007 SITC rev. 3 has been converted into SITC rev. 4.

Eurostat used for the correction the following data:

- The Community Innovation Surveys carried out every two years (Community Innovation Survey CIS)

- The high-tech trade data users (Comext) database,

- Using employment data of Human Resources in Science and Technology Human Resources in Science and Technology (HRST)

- The European Employment Survey (EU Labor Force Survey - LFS)

- Sector of Business Statistics (Structural Business Statistics SBS)

- And the European Patent Office.

Spatial breakdown is based on NUTS2 level and for EU, possible EU join and EFTA countries considering classification of NUTS2010/EU27 which is used by the European Commission regulations of $1059 / 2003$ and $31 / 2011$ and all the data is modified according to these classifications.

\footnotetext{
${ }^{3}$ NACE (1963- 1990), NACE 1 (1990-2002). NACE Rev. 1.1 (2002-2008) than NACE Rev. 2 from 2008 ${ }^{4}$ http://unstats.un.org/unsd/cr/registry/regcst.asp?Cl=28
} 
Although Szanyi et al (2009) declares that data at NUTS2 cannot be considered as relevant for regional level we accept the approach of Ketels and Sölvell (2005) and we used that aggregation level mainly because of the availability of the data.

Reviewing the data we found some difference between the regional data that we summarized as follows. Data from NUTS 2 level in Denmark has changed significantly in 2006 therefore we rejected to analyze the Danish results. Several regional changes in the NUTS3 level also appeared for example in Saxony-Anhalt from Germany, Canary Islands in Spain, in 40 LAU1 small regions in Poland but these changes happened on a lower aggregation level then our focus so it doesn't effected our results. There was a total recodification for Sweden in 2006 but only the names not the actual spatial borders changed itself. These changes also happened in NorthernEastern Scotland, in the Scottish Highlands and in different areas of the United Kingdom.

Considering all the possible regional labor data we analyzed $465^{5}$ regions for 14 years according to the knowledge intensive approach interpreted above for 15 different sectors. This could mean 97.650 pieces of data. The knowledge based differentiation also has different levels. From these we only used the lowest observable level (shown on the next figure) where we have four manufacturing and six service sectors. From our research results all the possible intermediate levels (manufacturing + service, high-tech/medium-tech/low-tech) levels can be derived.

Besides that for NACE rev. 1.1. National level data between 1994 and 2008 are also available but this level is considered as too abstract from our point of view as well. ${ }^{13}$

\footnotetext{
${ }^{5}$ Which includes NUTS 2-inch-wide data for all 28 EU countries as well as EFTA and candidate countries data.
}

All data have been revised by the Eurostat in 23.06.2013 and metadata has been checked in 19.09.2014.

For the comparison and the correlational study we used the NUTS2 level of GDP per capita data of Eurostat. Not every single piece of information was available in parallel so not every correlational comparison could be performed. After the pre-check of the data we left only 20 country from the 33 that were in the database. The reason for that was the outlier data of employment and the lack of data of GDP per capita in most of the cases. After the reclassification of the statistics in some regions severe drops and increases had appeared in employment data so we had to clean these data. According to all the mentioned factors we had to interpret our results only for that 20 countries with reliable data.

After clearing all the data and adopting them to NUTS2 level we started our correlation calculations with the use of SPSS Statistics 23. After the cross-check for significance ( $\mathrm{p}$ parameter) we summarized the data for four manufacturing and six service sectors.

All the following results will be interpreted to these sectors and to the mentioned regions. 


\section{Manufacturing}
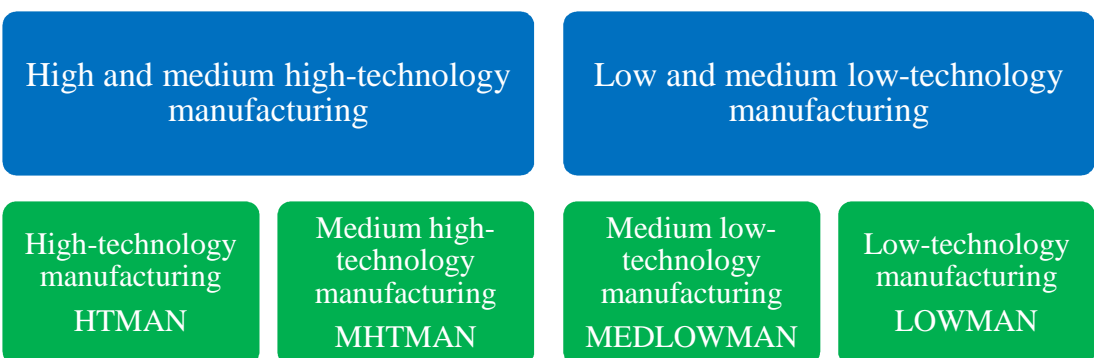

Low-technology manufacturing LOWMAN

Figure 1: Investigated knowledge intensive sectors in Manufacturing Source: Authors' edit - 2016

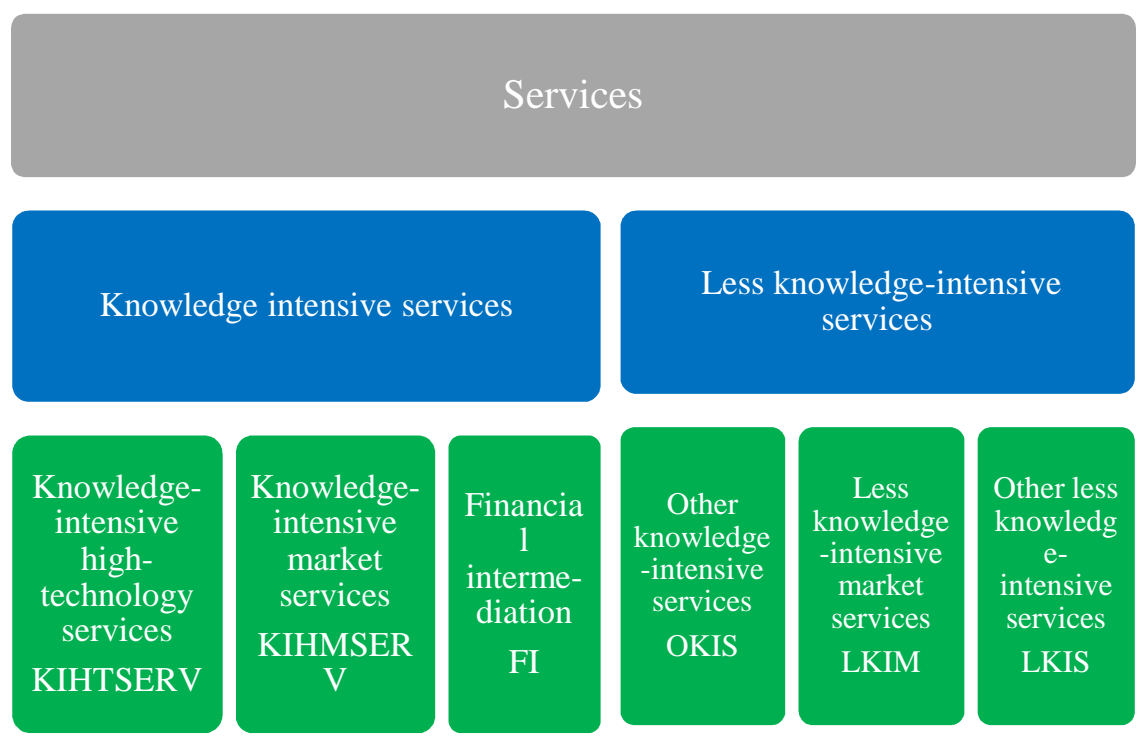

]Figure 2: Investigated knowledge intensive sectors in Services Source: Authors' edit - 2016

In the analytical part we combined different methods to interpret our results. We researched and presented:

- Regional results,

- Sectoral results,

- And country specific results if necessary.

We also made graphical illustration where significant data was available for the specific regions. In this paper we are only focusing on the sectoral results and on the suggestions that could be applied for crossborder co-operations.

\section{European sectoral results}

In order to interpret the results on the scale of the European Union (not only on 28 national level) we created the maps of the different sectors where we signed the regions with positive correlation with a red "hot-spot" to see where these regions are located. Although we must highlight the constraints of this approach. Only the homogenous knowledge intensive clusters are shown in these maps so horizontal cooperations cannot be visualized in this way and the details of the database may also give some difficulties when we would like to create regional policies based only on this approach.

To create a better map we should have fourdigit deep employment data that could be used below the regional level, but this data was not available for the whole EU. 
There are some regions where we instinctively would search for hot-spots that doesn't appear on these maps (Swiss bank sectors for instance). The lack of data is responsible for these kinds of deficiency but altogether the results have shown many times the existing or potential co-operations between border regions, and in many cases the great industrial regions have been detected which gives a positive impact on quality of life. In this study we didn't want to show neighboring relationship but the approach is highly suitable for that as well with some changes.

Just to have a clear understanding about the labor changes in the period we summarized the change of the share of labor market in the starting and ending period of the study regarding the different sectors which is shown on the next figure.

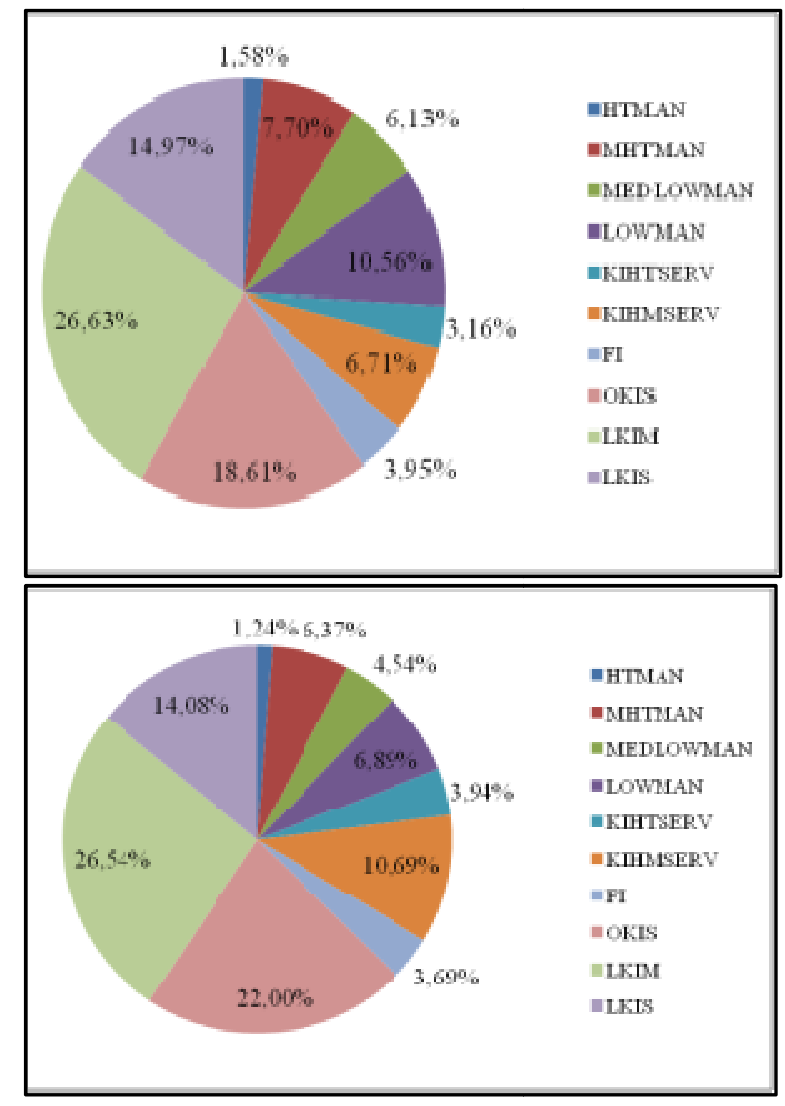

Figure 3: The weight of the sectors in the labor market for the sample countries between 1994-2008 - Source: Authors' edit - 2015
Figure 3 well represents that significant change in the investigated period happened only a several times. The share of every manufacturing sector and the other less knowledge intensive services dropped, while the knowledge-intensive market services and the other knowledge intensive services had a higher rate with 4 percent. This is of course an average data for all the countries for the whole period but it is easy to accept that in the total employment structure there were slightly less changes than in the regional specialization and concentration. Employment based location quotient changed more dramatically from time to time as the whole labor structure in Europe therefore the only general finding is the shift from manufacturing to services.

\section{High-technology manufacturing}

This sector consists of pharmacy, computer, electronic device and optical product manufacturing, just as aerospace equipment production. Starting with the last group: there is no reliable data available from Midi-Pyrenees region (FR62), the center of European aircraft manufacturing, therefore the effect of Airbus factory on this map is not visible. The involvement of SouthernGerman and Czech industrial regions is however perceptible, and Greater Manchester region is outstanding as well. If we would like to create a production chain of geographical and sectorial sense from the actors of this sector Hungary is in a fortunate position due to the fact that two neighboring countries (Slovakia and Austria) and also Germany - our most important partner in economic relations demonstrate positive effect in this area. A North-German, Dutch, Belgian cooperation in this area also seems conceivable. The Spanish and Italian results, given they geographically separately occur, might be of interest to national economic policy. 
It is important to emphasize that hightechnology manufacturing incorporates a much narrower category than an average person or even a policy maker would expect. This sector ignores biotechnology or engineering industries in calculations, while they could play leading role in any developed economy, therefore may not always the developing of most value added industry is the most useful when drawing up an economic policy path. The above described is shown on Figure 4.

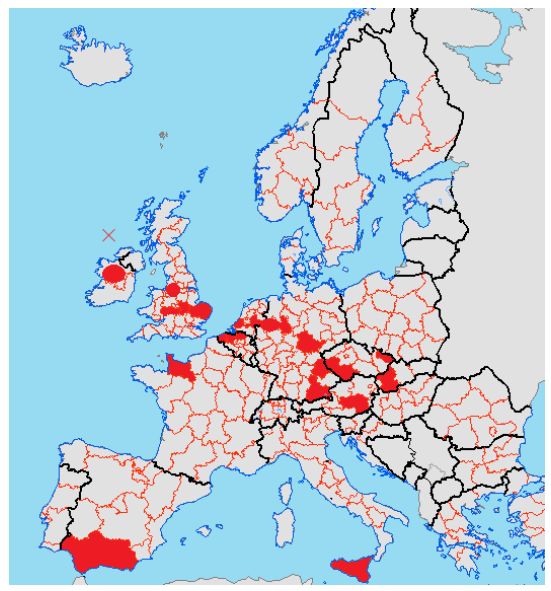

Figure 4: Positive correlation regions in high technology manufacturing sector - Source: Authors' edit using Eurostat GISCO 2014 - 2015

\section{Medium high-technology manufacturing}

The strength of disciplines operating with already existing knowledge elements are especially important for an economy in evolving a stable industry. Medium hightechnology manufacturing includes automotive industry, in particular, which is key element of Hungarian and European (mostly German) economies. This sector also includes all machine production activities, chemical industry and armaments production. Compared to the previous sector we can find medium high-technology manufacturing centers in more countries, specialization of Bavaria and BadenWürttemberg provinces in Germany, Western-Hungarian region in Hungary, and Western-Romanian region including
Timisoara also appears to be effective in improving welfare. The greatest focal points are the Belgian-French-DutchGerman borders which are part of the classically developed Ruhr Area and also the so called "Blue Banana" including the most developed European areas. This is the area which showed a "positive-labeled" region in every sector. One of Ireland's regions also showed positive correlation between industrial sectors and GDP, which could be a result of the "Irish Miracle". In Hungarian context the German cooperation still seems to be good solution, and the rapidly growing Timisoara and WestRomanian region could establish an innovation chain as well. The above described is shown on Figure 5.

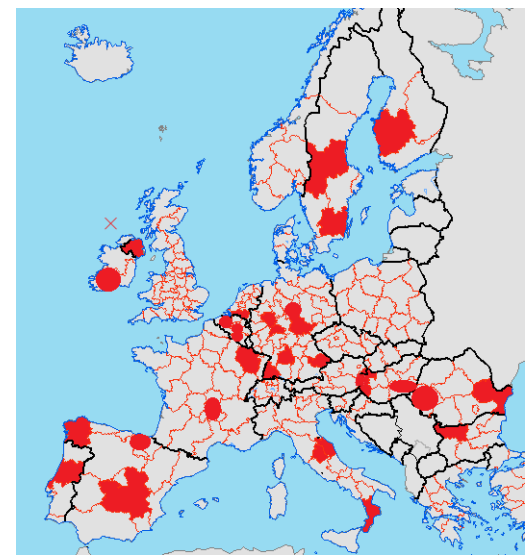

Figure 5: Positive correlation regions in mediumhigh tech manufacturing - Source: Authors' edit using Eurostat GISCO 2014 - 2015

\section{Medium low-technology manufacturing}

As in most of the cases when investigating manufacturing several German regions Ruhr Area, Belgian-Dutch borders showed positive correlation, and so did the majority of Spain. From Hungary's point of view the cooperation with Slovakia may be interesting as this sector, including metal industry, metal manufacturing and rubber industry, shows strong correlation with GDP per capita in Eastern-Slovakian and Northern Great Plain region in Hungary as well. 
Here the map draws the attention to the establishment of a new industrial relation system. This sectors appears in several regions in Visegrad countries and neighboring EU countries as a "hot spot", therefore in addition to specialization it highlights the importance of cooperation as well. The above described is shown on Figure 6.

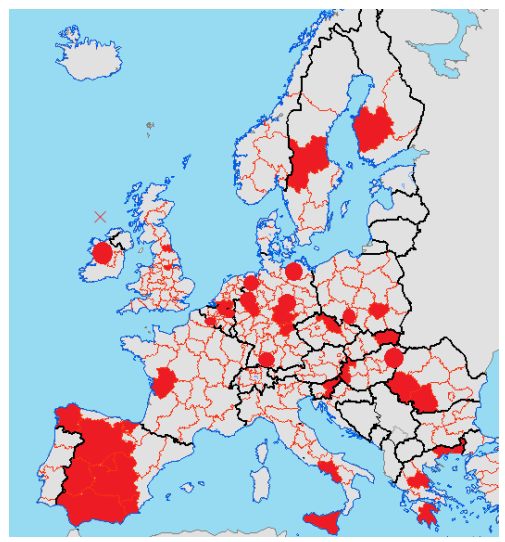

Figure 6: Positive correlation regions in medium low-tech manufacturing - Source: Authors' edit using Eurostat GISCO 2014 - 2015

\section{Low-technology manufacturing}

Low-technology manufacturing covers the entire segment of light industry, the food and beverage industry and the subset of all manufacturing industrial activities which are not included in the previous segment. While in 1995 average $10.56 \%$ of employed people worked in this sector, to 2008 this percentage dropped to $6.89 \%$. This value, however, still remains the 5th largest occupational category in the countries examined. No conclusion can be drawn on supranational level, but on national level Germany's sporadic structured industry and Romania's industrial structure is clearly visible. In Romania it is practically the largest hot spot: it showed the biggest positive correlation on the most extensive area. In case of Ireland, as in all manufacturing areas, found positive correlation here as well. In Hungary the
Western-Hungarian region is prominent from low-technology manufacturing perspective. However it is important to realize that the decline of economic performance of agriculture, and the increase of the role China's light industry in the recent decades resulted in the decline of textile and clothing industry (part of lowtechnology manufacturing) all over Europe. The above described is shown on Figure 7.

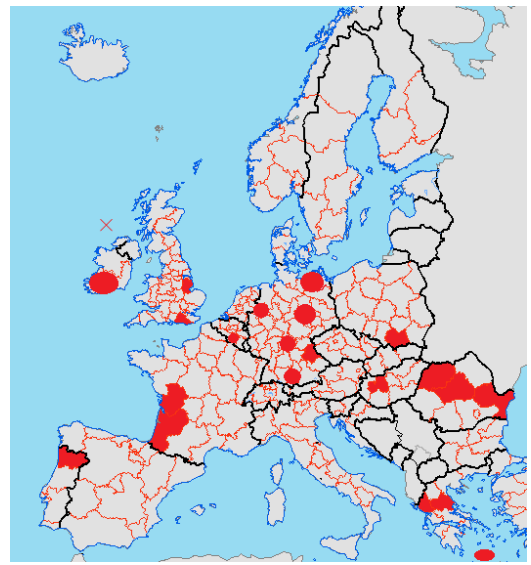

Figure 7: Positive correlation regions in low-tech manufacturing - Source: Authors' edit using Eurostat GISCO 2014 - 2015

\section{Knowledge-intensive high-technology} services

High-technology services typically include information-technology and film industry, as well as certain R\&D activities. Cologne in Germany as a regional center, Munich as an R\&D center, and Lisbon metropolitan region stands out in these areas. As hightechnology manufacturing neither this sector was a major employer, in 2008 average $3.94 \%$ of employed people worked in this sector. During maintaining the idea of knowledge-based economy, however, we can expect this sector to strengthen and the profiled centers to grow further. The above described is shown on Figure 8. 


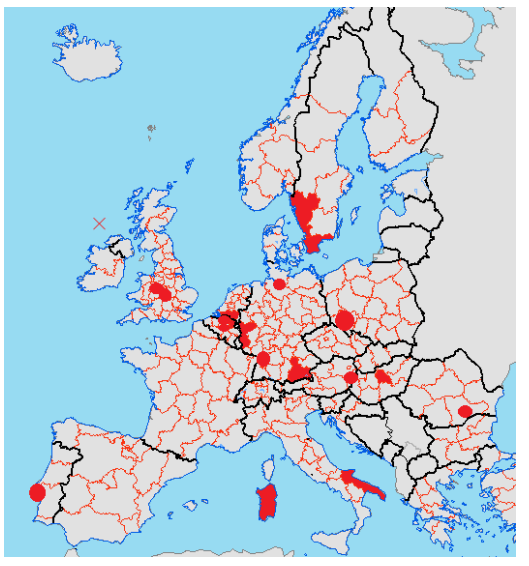

Figure 8: Positive correlation regions in knowledgeintensive high-technology services - Source: Authors' edit using Eurostat GISCO 2014 - 2015

\section{Knowledge-intensive market services}

The fastest growing in the sample was this sector, which includes air and water transportation, legal and business consulting, market research and other scientific and technical activities as well. It is obvious that with the retreat of industrial production the demand for services related to corporate management has increased at the same time that has also been profitable and useful in terms of regional development. Well-performing regions in manufacturing sector also proved to be hot spots in this category as well, namely the Belgian-Dutch-German-French border areas and three regions of Spain. It should be noted region of Galicia which was a hot spot in nearly all sectors, also Andalusia and Castilla-La-Mancha regions are performed well in the analysis. Unfortunately none of the Hungarian regions show up in this comparison, even though the sector increased with average $3.53 \%$ from 1996 to 2008 reaching the highest growth among all sectors. The above described is shown on Figure 9.

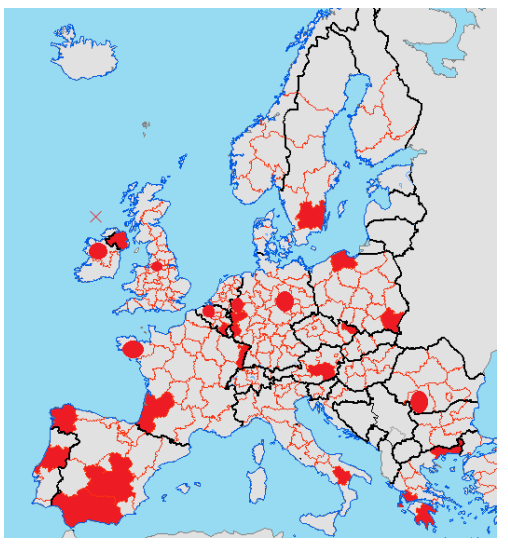

Figure 9: Positive correlation regions in knowledgeintensive market services - Source: Authors' edit using Eurostat GISCO 2014 - 2015

\section{Financial intermediation}

In case of financial intermediation we expected that metropolitan regions and adjacent existing financial centers will appear as hot spots in all analyzed countries. However our expectations haven't met because not all analyzed regions provided significant results. London as the largest financial center in Europe and Edinburgh as regional center in the UK, Vienna in Austria, Bratislava in Slovakia and Lisbon in Portugal show up as hot spots. We observed a very specific segregation in east-west direction in Germany that followed the borders of the two largest and wealthiest provinces, Bavaria and Baden-Württemberg. Is considered to be that the relatively wealthy population and successful entrepreneurial sector in these areas showed higher demand for financial services which resulted in such a concentration in this regions. At the same time, however, we exclude the possibility that the formation of developed financial system resulted in further increase in welfare in the respective regions. The above described is shown on Figure 10. 


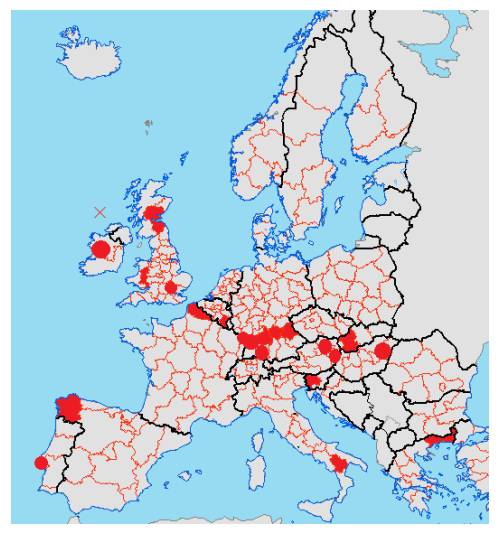

Figure 10: Positive correlation regions in financial intermediation- Source: Authors' edit using Eurostat GISCO 2014 - 2015

\section{Other knowledge-intensive services}

This sector reached the second highest growth among the countries of the sample, but not without reason, because the increase of government's involvement resulted in the growth of public administration's importance, meanwhile demand for services related to education, health, arts and sports activities has also increased during the development of welfare states. In terms of the German sample the importance of this sector increased significantly, with $4.56 \%$, yet it hasn't become driving force in the economy, we can hardly find any hot spots among the German regions. The sectoral distribution of hot spots is highly disperse here as well, therefore development of cross-border services is not supported by the analysis. However, this doesn't mean it wouldn't be necessary because we know on the basis of our everyday experiences that both in healthcare and education appears a suction effect that established health tourism and increases the number of foreign students especially in higher education. Future economic policies should pay attention to other knowledge-intensive services as well due to the reason that changes in consumption patterns may result in further growth in importance of this sector, therefore it could play an important role in increasing welfare. The above described is shown on Figure 11.

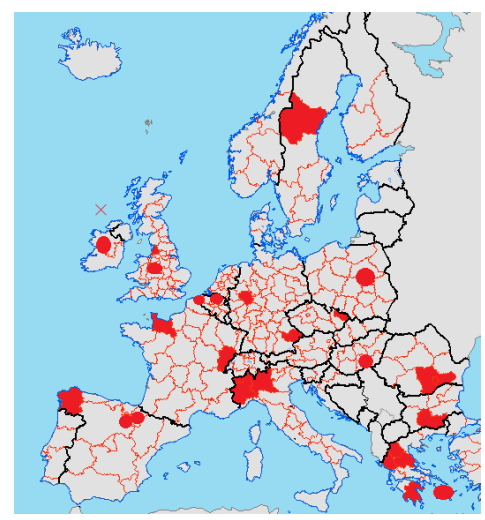

Figure 11: Positive correlation regions in other knowledge intensive services - Source: Authors' edit using Eurostat GISCO 2014 - 2015

\section{Less knowledge-intensive market services}

In the whole sample throughout the whole timeline of the study this sector has the biggest labor power employing around 26\% of all the employed people in Europe. This is easy understand because wholesale and retail activates, logistics and warehousing but also some part of tourism is classified into this sector. Following the patterns of the industrial centers the most of the welldeveloped German regions have hot-spots in these areas. For Hungary it can be interesting that on our western border and on the Austrian and Slovenian part we found positive correlation and maybe these sectors have export opportunities in the future. The hot-sports in France appeared in the densely populated regions with lot of industrial services and also in the juristically attractive landsides. These are represented on Figure 12. 


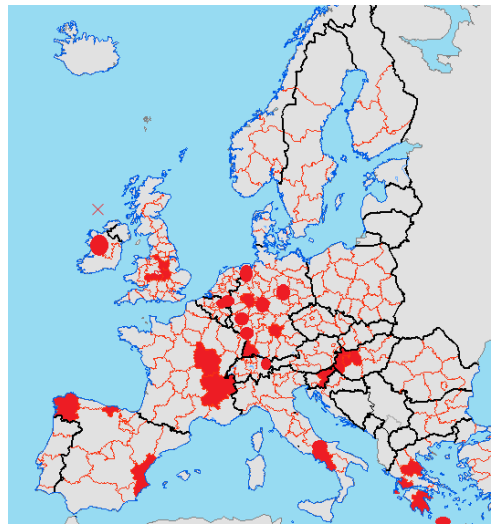

Figure 12: Positive correlation regions in lessknowledge intensive market services - Source: Authors' edit using Eurostat GISCO 2014 - 2015

\section{Other less knowledge-intensive services}

In this sector all the services are gathered which cannot be categorized into the ones above, where least knowledge is adopted for the work. The main parts of this sector is household work, postal activity, other services and everything that cannot categorized to elsewhere. As a fact that this sector does not have high added value but it exists in $\mathrm{n}$ every economy the disperse distribution of the hot-spots is reasonable. The interesting thing of this maps is that sectors with low knowledge intensity within Greece have ,good performance” according to correlation. Tit does not mean of course that lower knowledge sectors are the body of the Greek economy but we can say that during a period of increasing welfare these activities went through a concentration progress. That described above are shown in Figure 13.

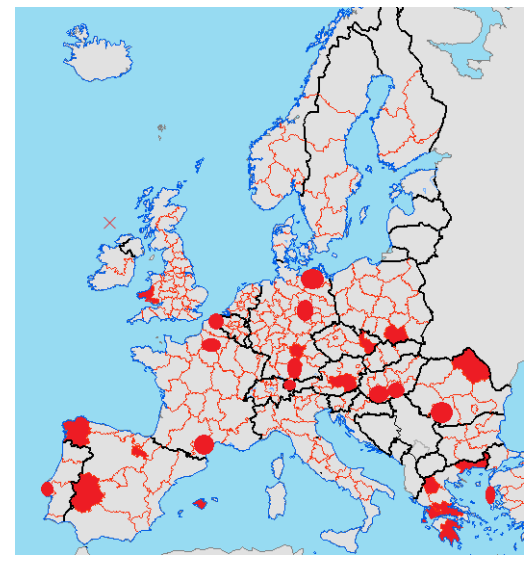

Figure 13: Positive correlation regions in other less knowledge intensive services - Source: Authors' edit using Eurostat GISCO 2014 - 2015

\section{Results of the research}

Concentration of all sectors with different knowledge intensity showed weak correlation on an average level, but medium high-technology manufacturing and hightechnology manufacturing from the industrial side and knowledge intensive market services and financial intermediation from service side showed the highest correlation with per capita GDP. These results can be interpreted as an average and of course regional differences occur and show different results in the different regions.

According to the regional interpretation of the results we used another approach showing the hot-spots where high correlation between the LQ and the per capita GDP was signed by the data. After the collection of all sectoral data we found that there are significantly more hot-spots in the regions of Germany, Belgium, Netherland and Eastern-France that in all the other regions. Within all the manufacturing and service sectors at least one hot-spot where identified in these regions. Altogether we found 42 cases where the regions of the so called „Blue Banana" appeared. 
Also there is a tendency that more and more regions in Eastern-Central Europe appears in the regions. These findings were observed especially within knowledge intensive market services, high technology manufacturing and in less-knowledge intensive market services.

Hot-spots (regions with positive correlation between GDP per capita and regional LQ) in every sector of manufacturing and services can be found in one of the most developed pat of Europe, namely in the „Blue Banana" region, but mainly in knowledge intensive market services and knowledge intensive high technology services hot-spots are oriented towards Central-Eastern Europe. With these results we confirmed that developed regions have concentrated and specialized industry, but the type of specialization is influenced by geographical, industry cultural and other factors. We can summarize our final thesis with the general assumption that there is no uniformed economic policy that can be delivered in every region in order to develop them. We assume that that according to the sectoral history of the region every place has its own special attributes therefore its development cannot be driven with top-down initiatives when there is no suitable industrial milieu for that. It cannot be proven as well that the higher knowledge intensive sectors are always the cornerstones of the economy, but in long-term we should consider their support as a strategic goal.

\section{References}

1. Ketels, C. - Protsiv, S. (2014): Methodology and Findings Report for a Cluster Mapping of Related Sectors, In: European Cluster Observatory REPORT, Center for Strategy and Competitiveness Stockholm School of Economics

2. Ketels, C. - Sölvell, Ö. [2005]: „Clusters in the EU 10 New Member Countries" Europe INNOVA

ftp://ftp.cordis.europa.eu/pub/innovationpolicy/studies/docs/studies/eucluster.pdf
3. Monfardini, E. - Probst, L.- Szenci, K.Cambier, B.- Frideres, L. (2012): "Emerging industries": report on the methodology for their classification and on the most active, significant and relevant new emerging industrial sectors http://www.clusterobservatory.eu/system/modul es/com.gridnine.opencms.modules.eco/provider s/getpdf.jsp?uid=b20af4e5-581d-4462-a3ebd178e4754011

4. Porter, M.E. (2003): The Economic Performance of Regions, Regional Studies 6-7. p.549-578

5. Szanyi M.- Csizmadia P.- Illéssy M.- Iwasaki, I. (2009): A gazdasági tevékenység sürüsödési pontjainak (klaszterek) vizsgálata. Statisztikai Szemle. 87. 9. p. 1-17. 